\title{
Rare monomorphic epithelial intestinal T-cell lymphoma of the stomach with a giant gastric perforation rescued by liver-covering sutures followed by a total gastrectomy and lateral hepatectomy: a case report
}

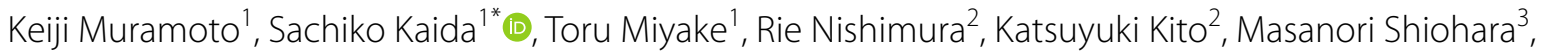
Ryoji Kushima ${ }^{3}$, Tomoharu Shimizu ${ }^{4}$ and Masaji Tani ${ }^{1}$

\begin{abstract}
Background: Monomorphic epitheliotropic intestinal T-cell lymphoma (MEITL), a type of peripheral T-cell lymphoma, rarely involves the stomach as the primary organ. Advanced MEITL, for which there is currently no established treatment, causes gastrointestinal perforations and is characterized by a poor response to chemotherapy.

Case presentation: A 69-year-old man had undergone chemotherapy for MEITL of the whole stomach. He subsequently developed acute abdominal pain, and computed tomography revealed a giant perforation in the anterior gastric wall adjacent to the lateral segment of the liver. The perforation was rescued through closure with livercovering sutures. Thereafter, a total gastrectomy and a left hepatectomy were performed and he recovered enough to tolerate oral intake. However, despite ongoing chemotherapy, the patient died 83 days after the gastric perforation (10 months after being diagnosed with the lymphoma) owing to rapid progression of the MEITL.
\end{abstract}

Conclusion: In the rare case of a giant gastric perforation after chemotherapy for gastric MEITL, rescue is possible through liver-covering sutures followed by a total gastrectomy and lateral hepatectomy.

Keywords: Monomorphic epitheliotropic intestinal T-cell lymphoma, Gastric lymphoma, Perforation, Hepatectomy

\section{Background}

Enteropathy-associated T-cell lymphoma (EATL) is classified as a rare type of peripheral T-cell lymphoma of the gastrointestinal tract, accounting for less than $1 \%$ of nonHodgkin lymphoma [1]. In the first place, EATL shows specific findings of villi atrophy for a pathological feature [2]. EATL occurs most frequently in the small intestine, and rarely occurs in the stomach at $8 \%$ [3].

\footnotetext{
${ }^{*}$ Correspondence: kaida@belle.shiga-med.ac.jp

1 Department of Surgery, Shiga University of Medical Science, Seta,

Tsukinowa-cho, Otsu, Shiga 520-2192, Japan

Full list of author information is available at the end of the article
}

EATL can be classified into two different types according to the 2016 World Health Organization classification of lymphoid neoplasms [4]. Type 1 EATL, also known as classic EATL, develops against the background of celiac disease and, therefore, has a high incidence in Europe and North America. It is often the cause of death in patients with refractory celiac disease. Type 2 EATL, which is not associated with celiac disease, is named monomorphic epitheliotropic intestinal T-cell lymphoma (MEITL) and is characterized by the infiltration of monomorphic lymphoma cells into the ductal epithelium. Both EATL types have different immunohistochemical characteristics [1]. Classic EATL and MEITL often form multiple ulcers and 
cause intestinal perforation, and it is considered to have a clinically aggressive course. We report a rare case of gastric MEITL perforation after chemotherapy.

\section{Case presentation}

A 69-year-old man presented with epigastric pain. An upper gastrointestinal endoscopy scan revealed irregular ulcers in the lesser curvature of the stomach (Fig. 1). Hematoxylin and eosin staining of the biopsy sample from the stomach lesions showed intraepithelial infiltration by atypical lymphocytes. Immunohistochemical staining for T-cell surface markers revealed a CD3(+), CD4(-), CD5(-), and CD7(+) immunophenotype.

The patient was diagnosed with malignant primary gastric lymphoma, because (1) the ${ }^{18} \mathrm{~F}$-fluorodeoxyglucose (FDG) positron emission tomography-computed tomography can revealed accumulation of FDG at the stomach wall only, and (2) no abnormal lesion was evident from the colonoscopy and small intestinal endoscopy scans.

Eight courses of first-line CHOP therapy (cyclophosphamide $750 \mathrm{mg} / \mathrm{m}^{2}$, doxorubicin $50 \mathrm{mg} / \mathrm{m}^{2}$, vincristine $1.4 \mathrm{mg} / \mathrm{m}^{2}$, and prednisolone $100 \mathrm{mg} / \mathrm{bid}$ ) were administered to the patient. Consequently, his gastric ulcers tended to increase (Fig. 1), and his CT scans revealed that the tumor diameter in the ulcer area had increased by $61 \%$ (from 21 to $34 \mathrm{~mm}$ ). The soluble interleukin-2 receptor level had also increased from $682 \mathrm{U} / \mathrm{mL}$ prechemotherapy to $1170 \mathrm{U} / \mathrm{mL}$ after the eight courses of chemotherapy. Because of the poor control of the tumor, we switched to pralatrexate $\left(30 \mathrm{mg} / \mathrm{m}^{2}\right)$ as the secondline treatment. However, the patient developed acute abdominal pain on the fourth day following the last cytotoxic drug administration. Physical examinations revealed board-like stiffness of the abdomen, a low blood pressure of $88 / 52 \mathrm{mmHg}$, and a pulse of 88 beats $/ \mathrm{min}$. Laboratory examinations revealed a hemoglobin count of $6.4 \mathrm{~g} / \mathrm{dL}$, a white blood cell count of $6400 / \mu \mathrm{L}$, and a C-reactive protein level of $5.14 \mathrm{mg} / \mathrm{dL}$. The abdominal CT scan revealed pyloric stenosis, a large amount of residual fluid in the stomach, and extensive gastric wall defects on the side of the lesser curvature of the gastric body (Fig. 2). The patient was diagnosed with peritonitis due to a hemorrhagic gastric perforation, and an emergency laparotomy was performed. Necrosis of the gastric mucosa was observed around the giant perforation, and the tumor had invaded the lateral segment of the liver. Because it was difficult to close the perforation site with a simple suture, the perforated part was emergently closed by suturing the lateral segment of the liver and the stomach wall together (Fig. 3). Although the patient needed 11 days of recovery in the intensive care unit after surgery, his general condition improved. With regard to the therapeutic strategy, many physicians on the cancer board had concluded that a tumor resection should be done for allowing oral intake; therefore, a total gastrectomy and a partial hepatectomy were performed 39 days after the first emergency operation. The patient was able to take a meal on the fourth day after the total gastrectomy.

Histopathological examination of the resected stomach and liver revealed atypical cell infiltration into the epithelium, destruction and deformation of the gastric wall, and infiltration into the liver and esophageal mucosa (Fig. 4). The microscopy investigation revealed that there were no

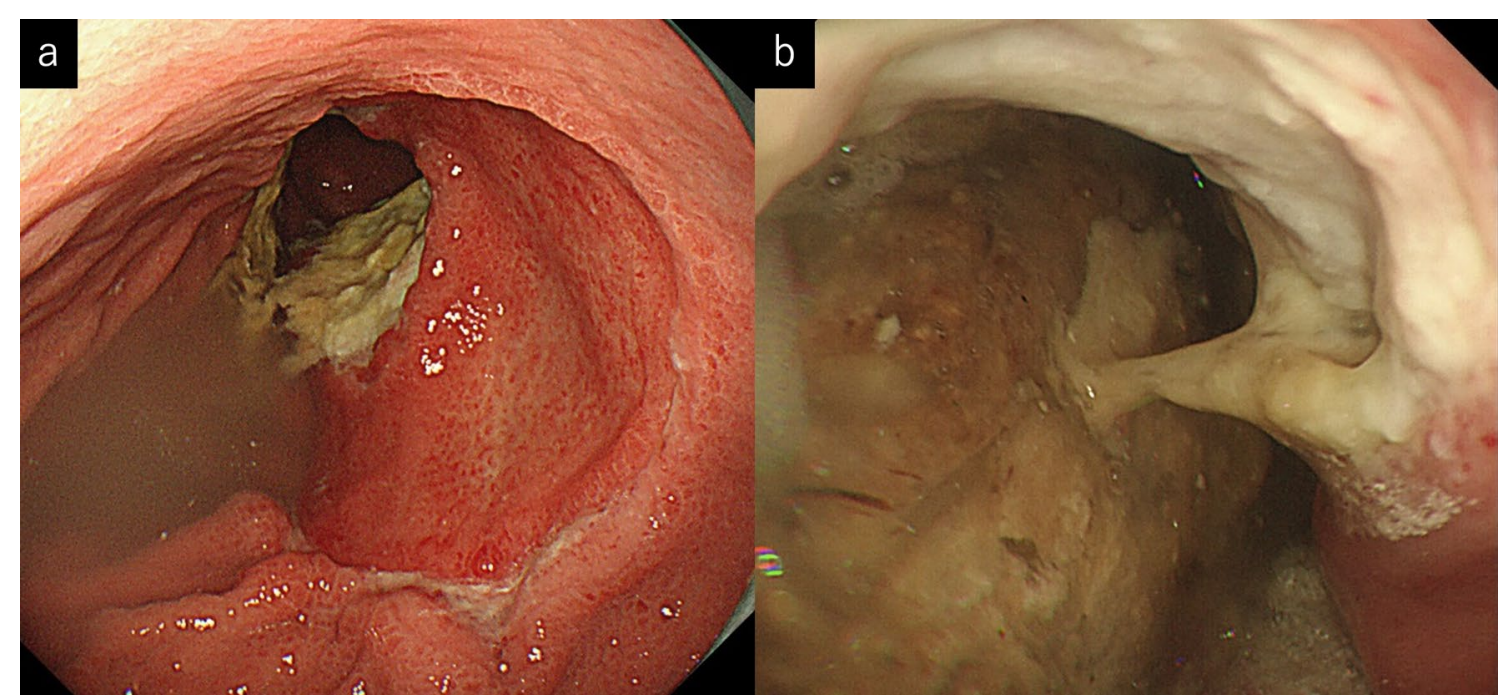

Fig. 1 a Upper gastrointestinal endoscopy showed irregular ulcers on the small side of the gastric body. $\mathbf{b}$ After 8 courses of CHOP (cyclophosphamide $750 \mathrm{mg} / \mathrm{m}^{2}$, doxorubicin $50 \mathrm{mg} / \mathrm{m}^{2}$, vincristine $1.4 \mathrm{mg} / \mathrm{m}^{2}$, prednisolone $100 \mathrm{mg}$ ) therapy, ulcers tended to increase 


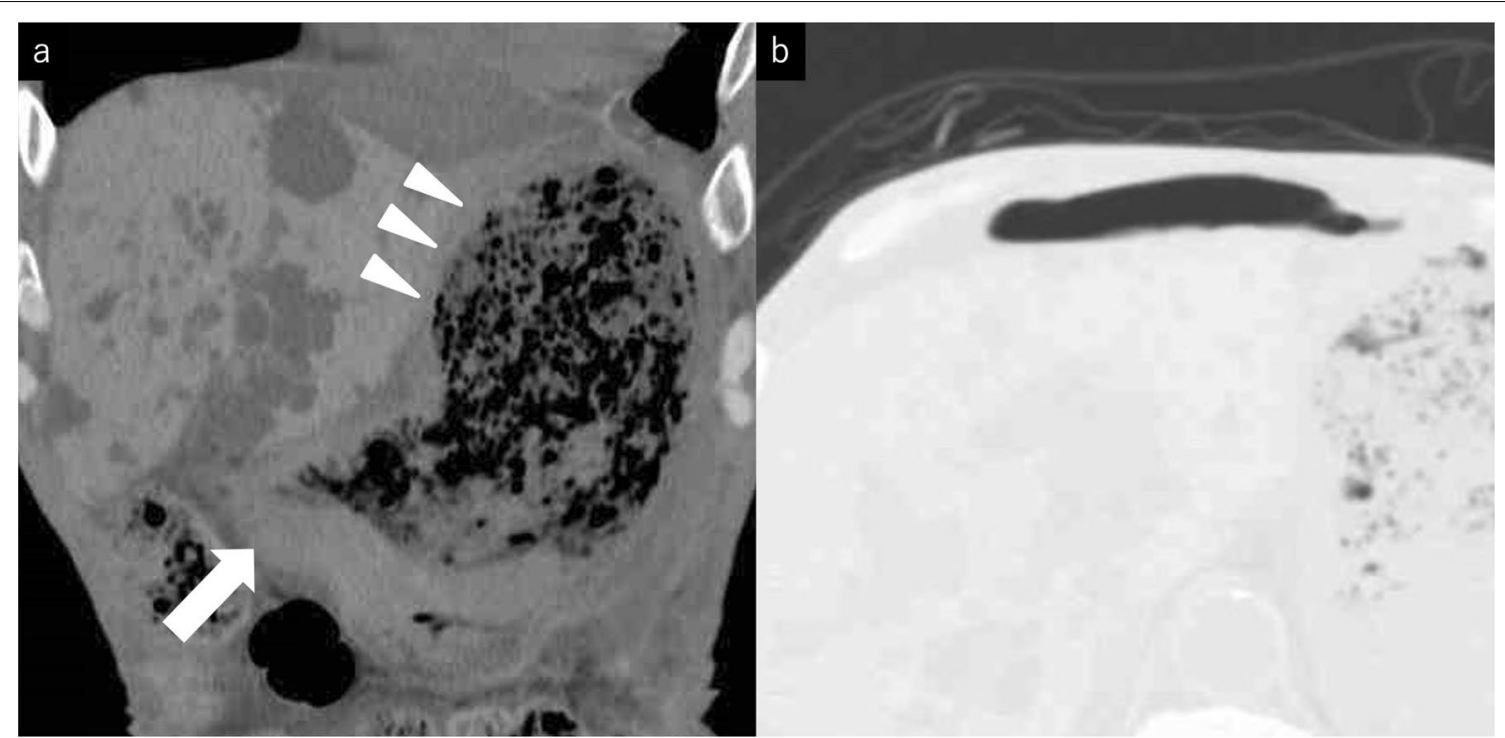

Fig. 2 a Abdominal CT showed pyloric stenosis (arrow) and extensive gastric wall defects on the lesser curvature of the stomach (arrowhead). b A large amount of free air was observed around the liver

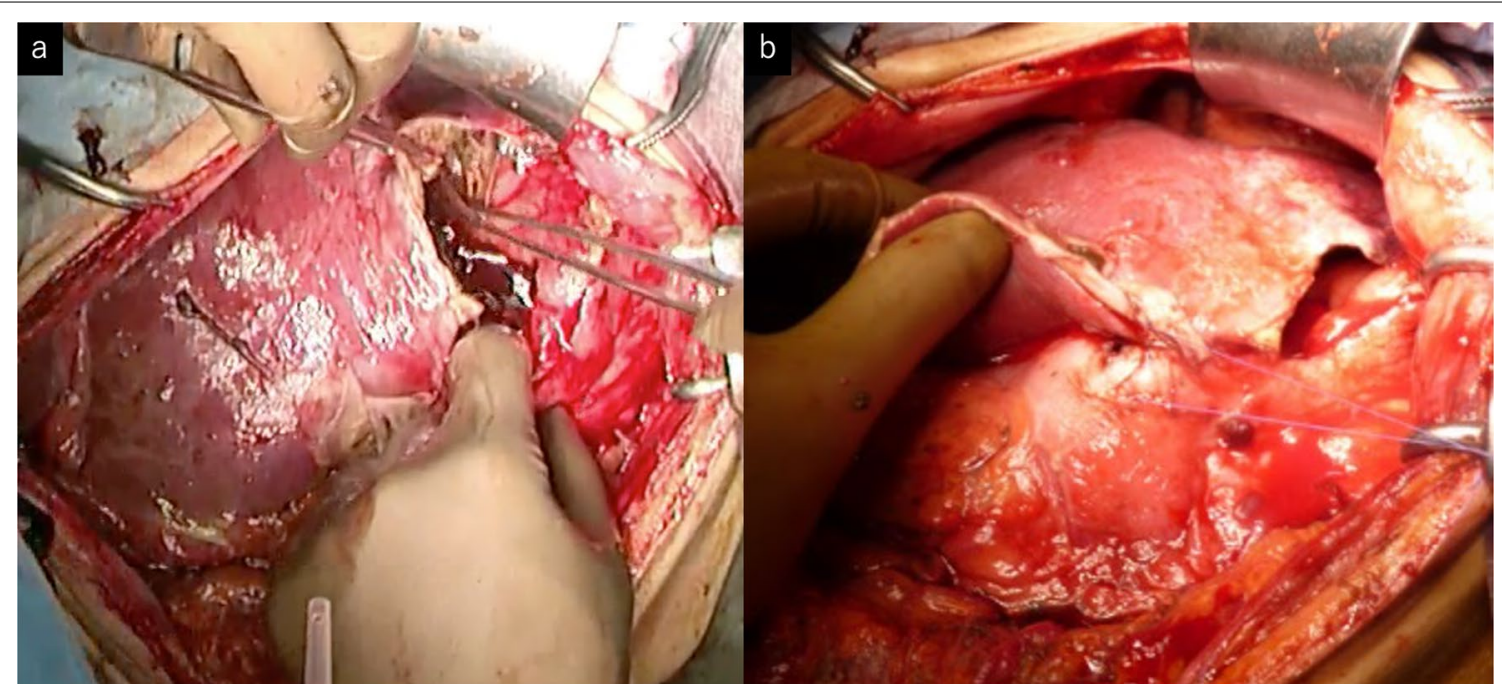

Fig. 3 a Anterior gastric wall was thinned and adhered to the lateral hepatic segment. The perforated part was $8 \mathrm{~cm}$ in diameter. $\mathbf{b}$ Entire stomach wall and the margin of the outer hepatic segment were sutured directly to close the perforation

tumor cells at the surgical margins. Upon immunohistochemical staining, $\mathrm{T}$ cells showed a CD3(+), CD4(-), CD5(-), and CD7(+) immunophenotype (Fig. 5) and gene rearrangement of the $\mathrm{T}$-cell receptor gamma-chain.

However, at 30 days after the secondary surgery, a CT scan revealed recurrent tumors in the pancreatic tail and the left diaphragm (Fig. 6). Therefore, IVE therapy (ifosfamide $3000 \mathrm{mg} / \mathrm{m}^{2}$, epirubicin $50 \mathrm{mg} / \mathrm{m}^{2}$, and etoposide $200 \mathrm{mg} / \mathrm{m}^{2}$ ) was performed as the third line of therapy but was unfortunately ineffective, and the patient died of respiratory deterioration due to pneumonia and pleural effusion on day 44 (83 days after discovery of the gastric perforation). The survival period was 10 months from the diagnosis of lymphoma.

The diagnosis of a primary malignant lymphoma of the digestive tract is based on the following diagnostic criteria of Dawson et al. [5]: (1) gastrointestinal lesions are predominant, and metastasis is only in the regional lymph nodes; (2) there is no swelling of the superficial lymph nodes; (3) there is no mediastinal lymphadenopathy on 


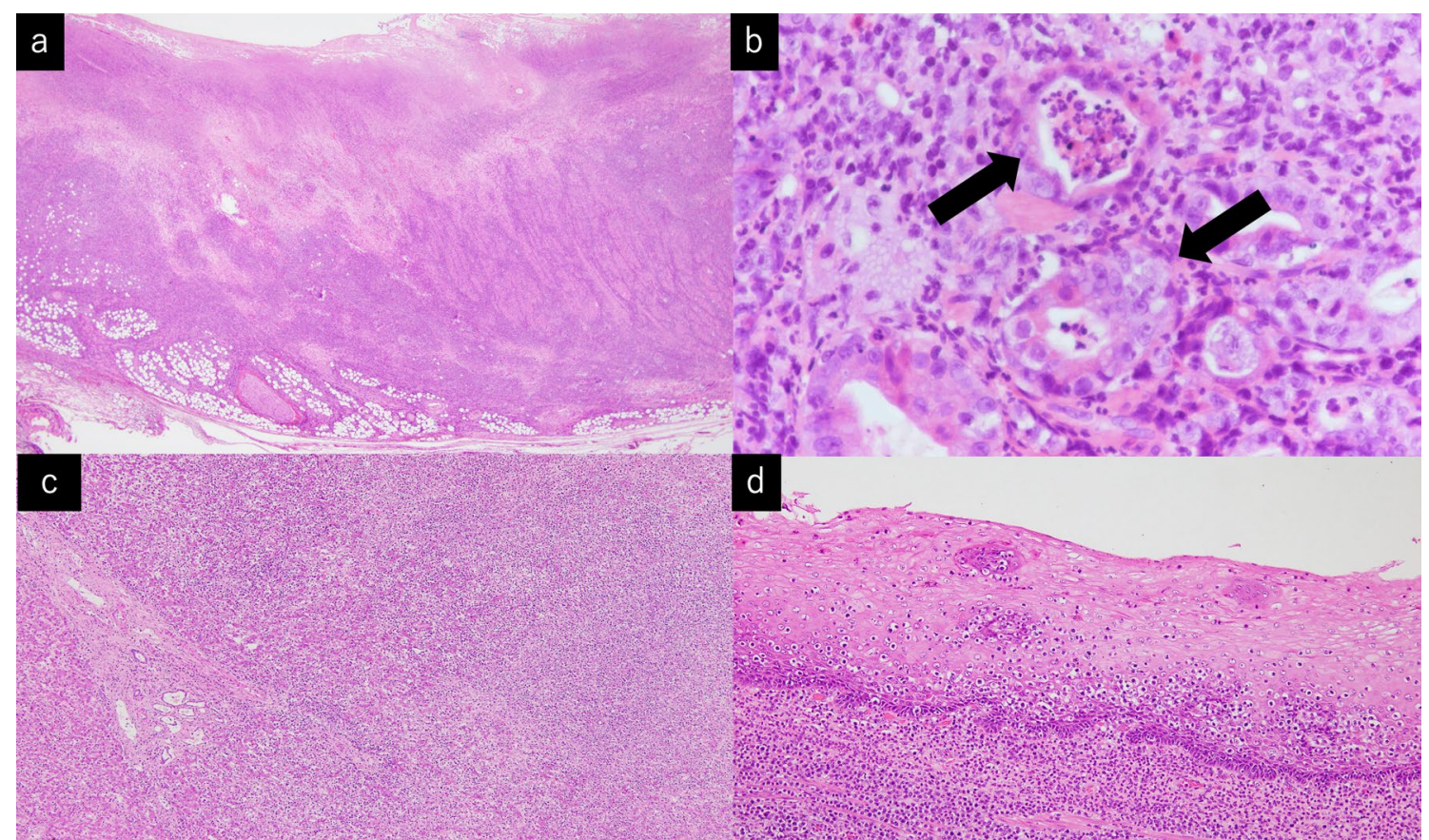

Fig. 4 a Histopathological findings showed deformation of the gastric gland structure. $\mathbf{b}$ infiltration of atypical cells into the epithelium and destruction. c Atypical cell infiltration into the liver. $\mathbf{d}$ Atypical cell infiltration into the esophagus

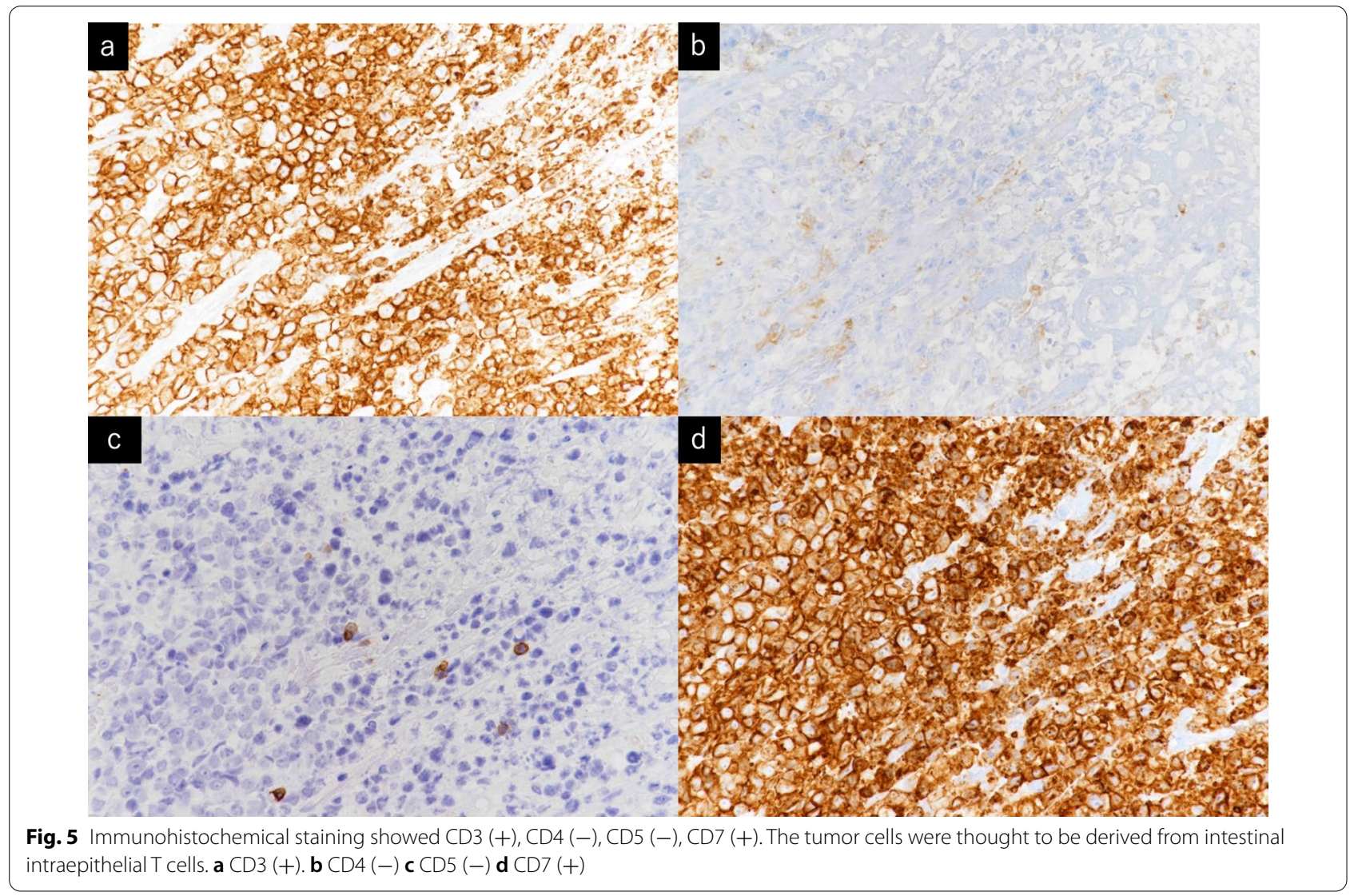




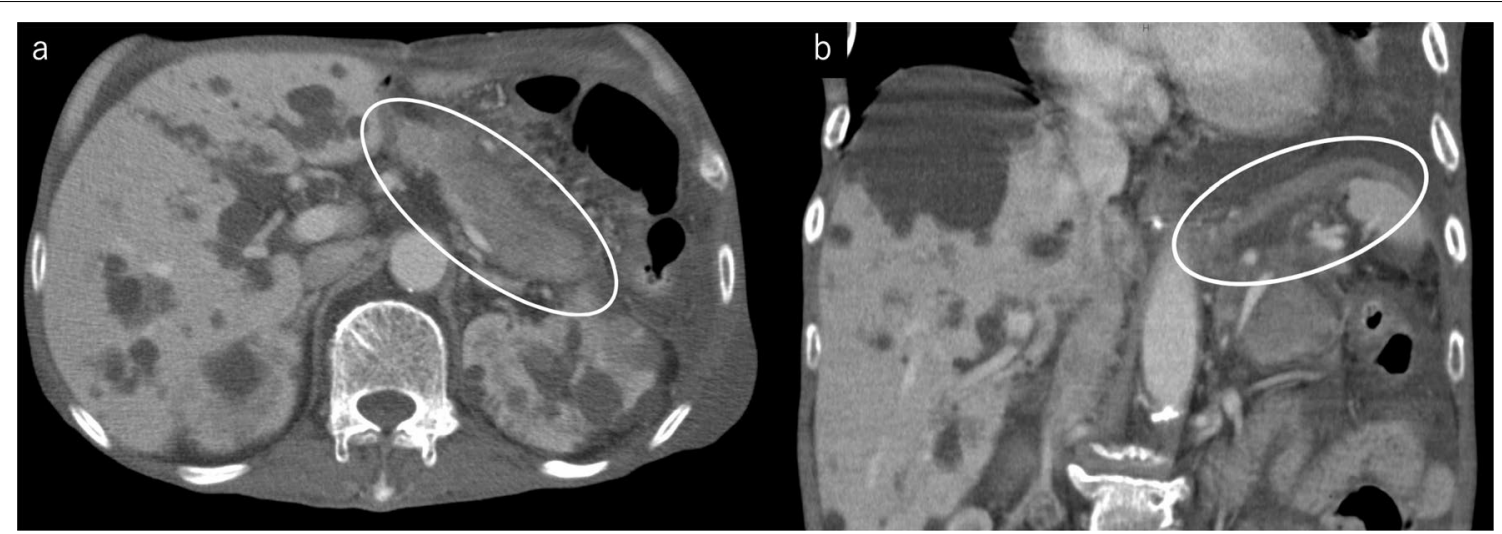

Fig. 6 a CT after total gastrectomy shows a low absorption region in the pancreas tail which is enlarged. $\mathbf{b}$ Left diaphragm was also thickened, and tumor infiltration was suspected in these lesions

simple chest X-rays; (4) hematological examination of the peripheral blood shows no whitening; and (5) there are no tumors in the liver and spleen. Primary gastric lymphomas derived from $\mathrm{T}$ cells are extremely rare. EATL and MEITL accounts for less than 1\% of all nonHodgkin's lymphomas [6]. Although primary gastrointestinal T-cell lymphomas occur predominantly in the small intestine, $8 \%$ of the tumors originate in the stomach [3]. In a PubMed search, we found only two patients with classic EATL or MEITL involving the stomach. One of these patients was a 73-year-old man who was diagnosed with classic EATL after a subtotal gastrectomy for a gastric perforation. The patient lived without any tumor recurrence or metastases within 3 months of followup [7]. The other patient, a 65-year-old male diagnosed with MEITL from gastrointestinal bleeding, had died 13 months after diagnosis [8].

Histologically, MEITL is characterized by the infiltration of atypical monoclonal lymphoid cells into the ductal epithelium, and unlike classic EATL, there is no infiltration of reactive inflammatory cells into the surroundings. Lymphoma cells have a CD3(+), CD4(-), CD5(-), CD7(+), and CD103(+) immunophenotype with T-cell receptor beta-chain $(-)$ expression and contain cytotoxic granule proteins [8]. In our patient, the tumor cells were considered to be derived from $\mathrm{T}$ cells in the intestinal epithelium, because they presented a CD3(+), CD5(-), CD7(+), and CD4(-) immunophenotype and had a recognized gene rearrangement of the T-cell receptor gamma-chain, resulting in the T-cell lymphoma diagnosis. On the basis of these immunohistochemical findings, the possibility of a primary lymphoma of the gastrointestinal tract, and the lack of a background of celiac disease, we diagnosed the patient as having MEITL. PTL is classified as a lymphoma of intermediate-grade aggressiveness. Specifically, MEITL and classic EATL proliferate around the gastrointestinal tract wall and often cause gastrointestinal perforations. According to Sasaki et al. [9], the median survival time was 8 months for patients with a single perforation and 2.35 months for those with multiple perforations.

Our patient was diagnosed with MEITL and had developed a gastric perforation while undergoing chemotherapy, whereupon emergency surgery was performed to cover the lateral segment of the liver and suture it to the defect of the stomach wall. After the improvement of his general condition, a total gastrectomy and a lateral hepatic segmentectomy were performed. Postoperatively, the patient was able to tolerate oral intake and received chemotherapy for the lymphoma.

The tumor in our patient was localized to the stomach and was classified as Stage I according to the gastrointestinal Lugano classification (1994) [10]. Based on the international prognostic index [11], which is a prognostic indicator for patients with an aggressive lymphoma, the tumor presented a low to intermediate risk (age 61 years and older, high lactate dehydrogenase). The median survival time following CHOP-based chemotherapy, which is commonly administrated for the treatment of malignant lymphomas, is reportedly 7.5 months $[12,13]$. Treatment is often not completed owing to adverse events or tumor progression. Although complete remission has been achieved in $35-40 \%$ of patients who completed treatment, relapse frequently occurs [14]. There are no established standard therapies for MEITL and classic EATL [15]. The median remission duration for both EATL types is only 6 months, and the 5-year survival rates are reported to be $9-22 \%$ [16]. In malignant lymphoma of the gastrointestinal tract, surgery is performed when tumor obstruction, hemorrhage or perforation has occurred or is expected to occur. It has been reported that the 
prognosis when the tumor can be completely resected is better than that when there is a residual lesion [17]. However, it has been reported that perforation or hemorrhage during chemotherapy for gastric malignant lymphoma is low frequency (less than 5\%) [18], and there is a risk that gastrectomy may delay the introduction of chemotherapy, and the decreased functional prognosis due to postoperative complications and postgastrectomy syndrome (dyspepsia and dumping syndrome) must be considered. In this case, prophylactic gastrectomy may have been considered before 2 nd line chemotherapy in view of the gastrointestinal perforation and peritoneal dissemination that occurred. The timing of the surgery is a limitation of this presentation, because the stomach is an organ with a thicker muscular layer than the small intestine and early perforation is difficult to predict. In the future, the early diagnosis of MEITL and the establishment of standard treatments are still necessary to improve patient outcomes.

\section{Conclusion}

We experienced an extremely rare case of primary gastrointestinal tract-associated T-cell lymphoma. It was possible to rescue the oncological emergency of a giant gastric perforation by suturing the lateral segment of the liver and the stomach wall together.

\begin{abstract}
Abbreviations
MEITL: Monomorphic epitheliotropic intestinal T-cell lymphoma; EATL: Enteropathy-associated T-cell lymphoma; FDG: ${ }^{18}$ F-Fluorodeoxyglucose; IVE: Chemotherapy with ifosfamide, epirubicin and etoposide cisplatin; PET-CT: Positron emission tomography-computed tomography; CHOP: Chemotherapy with cyclophosphamide, doxorubicin, vincristine and prednisolone; IVE: Chemotherapy with ifosfamide, epirubicin and etoposide cisplatin; PTL: Peripheral T-cell lymphoma; IPI: International prognostic index; LDH: Lactate dehydrogenase.
\end{abstract}

\section{Acknowledgements}

All authors acknowledge no forms of financial support, including technical assistance and advice. We would like to thank Editage (www.editage.com) for English language editing.

\section{Authors' contributions}

KM wrote the manuscript. TM and SK and KM performed surgery. RN and KK performed chemotherapy, MS and KR diagnosed histopathological findings. All authors read and approved the final manuscript.

\section{Authors' information}

All authors are members of the Japan Surgical Society and the Division of Department of Surgery.

Shiga University of Medical Science, Shiga, Japan, Seta, Tsukinowa-cho, Otsu, Shiga 520-2192, Japan.

\section{Funding}

The authors received no financial support for the preparation of this case report.

\section{Availability of data and materials}

All data analyzed during this study are included in this article.

\section{Declarations}

Ethics approval and consent to participate

Not applicable.

\section{Consent for publication}

The patient has consented to the publication of these features of her case, and her identity has been protected.

\section{Competing interests}

The authors declare that they have no competing interests.

\section{Author details}

${ }^{1}$ Department of Surgery, Shiga University of Medical Science, Seta, Tsukinowa-cho, Otsu, Shiga 520-2192, Japan. ${ }^{2}$ Department of Gastroenterology and Hematology, Shiga University of Medical Science, Seta, Tsukinowa-cho, Otsu, Shiga 520-2192, Japan. ${ }^{3}$ Department of Clinical Laboratory Medicine and Diagnostic Pathology, Shiga University of Medical Science, Seta, Tsukinowa-cho, Otsu, Shiga 520-2192, Japan. ${ }^{4}$ Medical Safety Section, Shiga University of Medical Science Hospital, Seta, Tsukinowa-cho, Otsu, Shiga 520-2192, Japan.

Received: 14 September 2020 Accepted: 28 January 2022

Published online: 07 February 2022

\section{References}

1. Swerdlow SH, Campo E, Pileri SA. The 2016 revision of the world health organization classification of lymphoid neoplasms. Blood. 2016;127(20):2375-90.

2. O'Farrelly C, Feighery C, O'Briain DS. Humoral response to wheat protein in patients with coeliac disease and enteropathy associated T cell lymphoma. Br Med J. 1986;293:908-10.

3. Delabie J, Holte H, Vose JM. Enteropathy-associated T-cell lymphoma: clinical and histological findings from the international peripheral T-cell lymphoma project. Blood. 2011;118:148-55.

4. Chan JK, Chan AC, Cheuk W. Type II enteropathy associated T-cell lymphoma: distinct aggressive lymphoma with frequent $\gamma \delta$ T-cell receptor expression. Am J Surg Pathol. 2011;35(10):1557-69.

5. Dawson IM, Comes JS, Morson BC. Primary malignant lymphoid tumors of the intestinal tract. Report of 37 cases with a study of factors influencing prognosis. Br J surg. 1961;49:80-9.

6. Kim YS, Choi YS, Park JS. Case of small bowel perforation due to enteropathy-type T-cell lymphoma. Yonsei Med J. 2009;50:859-61.

7. Wang L. A case of enteropathy-associated T-cell lymphoma (Type I) arising in stomach without refractory celiac disease. Diagn Pathol. 2012;7(172):1-6.

8. Chan TSY. Positron emission tomography computed tomography features of monomorphic epitheliotropic intestinal T-cell lymphoma. Hematology. 2018;23(1):10-6.

9. Sasaki Y. A case of ileal perforation due to EATL (enteropathy associated T-cell lymphoma) located in the gastrointestinal tract including the stomach and duodenum. Gastroenterol Endosc. 2017;59(6):1422-7.

10. Rohatiner A. Report on a workshop convened to discuss the pathological and staging classifications of gastrointestinal tract lymphoma. Ann Oncol. 1994;5(5):397-400

11. Vose J. International peripheral T-cell and natural killer/T-cell lymphoma study: pathology findings and clinical outcomes. J Clin Oncol. 2008;26(25):4124-30

12. Gale J, Simmonds PD, Mead GM. Enteropathy-type intestinal T-cell lymphoma: clinical features and treatment of 31 patients in a single center. J Clin Oncol. 2000;18(4):795-803.

13. Novakovic BJ, Novakovic S, Frkovic-Grazio S. A single-center report on clinical features and treatment response in patients with intestinal $T$ cell non-Hodgkin's lymphomas. Oncol Rep. 2006;16(1):191-5.

14. Daum S, Ullrich R, Heise W. Intestinal non-Hodgkin's lymphoma: a multicenter prospective clinical study from the German Study Group on Intestinal Non-Hodgkin's Lymphoma. J Clin Oncol. 2003;21(14):2740-6. 
15. Al-Toma A, Verbeek WH, Hadithi M. Survival in refractory coeliac disease and enteropathy-associated T-cell lymphoma. Gut. 2007;56:1373-8.

16. Sieniawski M, Angamuthu N, Boyd K. Evaluation of enteropathyassociated T-cell lymphoma comparing standard therapies with a novel regimen including autologous stem cell transplantation. Blood. 2010;115(18):3664-70.

17. Di Sabatino A, Biagi F, Gobbi PG. How I treat enteropathy-associated T-cell lymphoma. Blood. 2012;119:2458-68.

18. Maisey N, Norman A, Prior Y. Chemotherapy for primary gastric lymphoma: does in-patient observation prevent complications. Clin Oncol. 2004;16:48-52.

\section{Publisher's Note}

Springer Nature remains neutral with regard to jurisdictional claims in published maps and institutional affiliations.

\section{Submit your manuscript to a SpringerOpen ${ }^{\odot}$ journal and benefit from:}

- Convenient online submission

- Rigorous peer review

- Open access: articles freely available online

- High visibility within the field

- Retaining the copyright to your article

Submit your next manuscript at $\boldsymbol{\nabla}$ springeropen.com 